
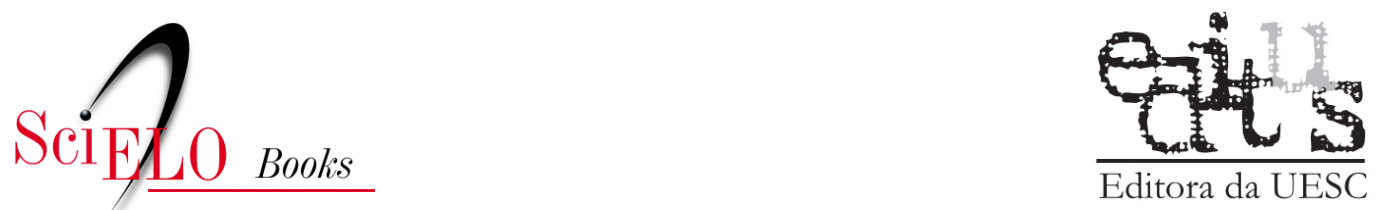

\title{
Representações da velhice no olhar dos jovens
}

\author{
Vania Herédia \\ Josiane Bonvolini
}

\section{SciELO Books / SciELO Livros / SciELO Libros}

HERÉDIA, V., and BONVOLINI, J. Representações da velhice no olhar dos jovens. In: D'ALENCAR, R. S., ed. A representação social na construção da velhice [online]. Ilhéus, BA: EDITUS. 2017, pp. 171-188. ISBN: 978-85-7455486-0. https://doi.org/10.7476/9788574554860.0009.

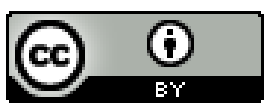

All the contents of this work, except where otherwise noted, is licensed under a Creative Commons Attribution 4.0 International license.

Todo o conteúdo deste trabalho, exceto quando houver ressalva, é publicado sob a licença Creative Commons Atribição 4.0.

Todo el contenido de esta obra, excepto donde se indique lo contrario, está bajo licencia de la licencia Creative Commons Reconocimento 4.0. 


\title{
REPRESENTAÇÕES DA VELHICE NO OLHAR DOS JOVENS
}

\author{
Vania Herédia \\ Josiane Bonvolini
}

Para entender que maturidade e velhice não são decadência, mas transformação, temos de ser preparados para isso (LUFT, 2010, p. 127).

Com o envelhecimento da população, a heterogeneidade na velhice tornou-se um fenômeno visivel. Entretanto, a heterogeneidade na velhice nos leva a pensar como esses velhos se prepararam para envelhecer e o que permaneceu no imaginário, como consciência desse processo. O estudo aqui realizado tem como objetivo apresentar as diversas percepções que os jovens têm sobre o envelhecimento humano a fim de fornecer elementos para a discussão sobre o tema, levando em consideração que a caminhada existencial pode ser planejada pelos jovens enquanto jovens.

Os registros desses testemunhos mostram a fragilidade da idealização por parte dos jovens do que vão enfrentar no seu processo de envelhecimento. Nessa direção, podese dizer que nem todos os velhos encaram a velhice da mesma forma e as reações, em relação aos seus comportamentos, são diferenciadas, o que também revela que a pre- 
paração ou a não preparação não foi comum. O estudo é de natureza qualitativa, exploratória e trata de narrativas de jovens sobre o envelhecimento. A pergunta norteadora questiona como eles se imaginavam com 92 anos, e suas narrativas constituíram o corpus deste estudo. A pesquisa foi realizada na disciplina de "Longevidade, Vida e Sociedade", oferecida aos cursos de graduação da Universidade de Caxias do Sul, de 2015 e 2016. Os entrevistados foram 45 alunos. Para a avaliação das narrativas, foi utilizado o método de análise de conteúdo, baseado na concepção de Moraes (1994, p. 2), cuja metodologia de pesquisa permite identificar as percepções dos entrevistados, a fim de compreender os significados que atribuem ao tema. Das narrativas, nasceram três categorias de análise que discorrem sobre as representações sobre a velhice pelos jovens.

O resultado do estudo evidencia a importância de uma educação para a velhice ao longo da vida, a fim de alertar aos mais jovens sobre a riqueza do processo que a vida proporciona ao ser humano. Beauvoir (1990, p. 10), parafraseando Proust, diz: " $E$ com adolescentes que duram um número bastante grande de anos que a vida faz velhos" e que "conservam as qualidades e os defeitos do homem que continuam a ser".

Dessa maneira, a intenção deste estudo atende à chamada de consciência por jovens sobre como esperam envelhecer. Mesmo que não seja comum essa reflexão, nos seus imaginários aparece o modelo daqueles que os educaram e das condições que vivenciaram com seus pais e avós, negando que a realidade de cada um possa modificar o seu processo de envelhecimento.

\section{Diversas concepções de velhice}

Por certo, os que não obtêm dentro de si os recursos necessários para viver na felicidade acharão execráveis todas as idades da vida. Mas todo aquele que 
sabe tirar de si próprio o essencial não poderia julgar ruins as necessidades da natureza. E a velhice, seguramente faz parte delas! Todos os homens desejam alcançá-la, mas ao ficarem velhos, se lamentam. Eis aí a inconsequência da estupidez! (Cicero).

Beauvoir diz que a velhice "não é um fenômeno estático; é o resultado e o prolongamento de um processo" (BEAUVOIR, 1990, p. 17). Diz ainda que "não poderia ser compreendida senão em sua totalidade; ela não é somente um fato biológico, mas também um fato cultural" (BEAUVOIR, 1990, p. 20). Essa concepção, muito utilizada nos estudos do envelhecimento, mostra que a velhice é um ciclo de vida que está conectado a todo o processo que o ser humano passou desde o nascimento, mas que ser velho é uma condição daqueles que conseguiram chegar nesse ciclo.

Caldas (2010, p. 19), quando trata de envelhecimento em termos biológicos, diz que o mesmo "compreende os processos de transformação do organismo que ocorrem após a maturação sexual e que implicam a diminuição gradual da probabilidade de sobrevivência”. Essa autora chama a atenção que o envelhecimento e o desenvolvimento "são processos que coexistem ao longo do ciclo vital" (2010, p. 19) e que aquele que envelheceu teve oportunidade de passar pelo processo.

Neri (2001, p. 27) tem a mesma concepção sobre o envelhecimento, utilizando a maturação sexual como ponto de referência, mas coloca que "esses processos são de natureza interacional, iniciam-se em diferentes épocas e ritmos e acarretam resultados distintos para as diferentes partes e funções do organismo". Entretanto, Neri (2001, p. 27-28) chama a atenção que "há um limite para a longevidade, estabelecido por um programa genético que permitiria ao organismo suportar uma determinada quantidade de mutações. Esgotado esse limite, o organismo perece".

Para cada época, a velhice estava associada a um atributo que justificava o ciclo vital e dava a ele respostas 
prontas como explicação coletiva. Muitos filósofos definiam a velhice pela idade e com atributos positivos, no sentido de acúmulo de experiências, de conhecimento, de saber acumulado.

Debert (1999, p. 13) alerta que à medida que a velhice assume uma visibilidade na sociedade contemporânea, ocorre um duplo movimento que marca essa visão, ou seja, de um lado a "socialização progressiva da gestão da velhice; durante muito tempo considerada como própria da esfera privada e familiar," e, de outro lado, "uma questão de previdência individual ou de associações filantrópicas, ela se transforma em uma questão pública." Esse cuidado da sociedade contemporânea não existia anteriormente como proteção do cidadão, reflete uma concepção homogênea daquele que envelhece e nesse sentido a representação do velho carrega uma forte tendência a homogeneização. Nessa direção, Debert esclarece que a velhice é "tratada como uma etapa da vida caracterizada pela decadência física e ausência de papéis sociais" (1999, p. 14). Entretanto, a autora chama a atenção de que o avanço da idade visto pelas fragilidades, perdas e dependência, torna-se responsável por representações marcadas por imagens negativas, calcadas na doença, no sofrimento e nas perdas. Alerta ainda que houve "um processo de reprivatização" da velhice onde a mesma resulta de responsabilidades individuais e nesse sentido ganha novas representações.

Debert (1999), quando trata da homogeneidade e da heterogeneidade na velhice, usa Guillemard (1986) que, por meio de três grandes conjuntos de mudanças estruturais, que afetaram os velhos no século $\mathrm{XX}$, mostra como foi a passagem dessa homogeneidade para a heterogeneidade. Nesse sentido, a associação de velhice à pobreza foi muito comum no período pós-guerra mundial, quando os idosos apresentavam características muito semelhantes. Entretanto, após a metade do século XX, quando muitos países pensam o sistema de aposentadoria como uma forma de 
garantia àqueles que trabalharam em sistemas de produção contínuos, que afetam as condições socioeconômicas dos velhos, tem-se uma mudança substancial na concepção e no dar-se conta da importância do envelhecimento. Percebe-se que o envelhecimento fica associado à perda de valor, quando o indivíduo não contribui para o mercado de trabalho, passa a ser ignorado por ele, e a visão de velho ganha um outro atributo negativo dado ao fato de não estar mais integrado ao circuito produtivo.

Nesse contexto, o século XX modificou a visão sobre o envelhecimento, à medida que as sociedades começaram a enfrentar o peso de parcelas bastante significativas pelo volume da população idosa mundial. Diriamos ainda que algumas sociedades, por meio de seus governos, começaram a se preocupar com o envelhecimento mundial. Em 1982, ocorre em Viena a primeira Assembleia Mundial do Envelhecimento Humano, onde se reúnem países para discutir estratégias e medidas que possam ajudar as sociedades a enfrentarem o envelhecimento de sua população. Nessa assembleia, que terá, posteriormente, continuidade, vinte anos depois em Madrid, são definidas Politicas para o Envelhecimento Mundial, levando em consideração os dados e as informações que tinham no momento. Na segunda Assembleia, que ocorre em Madrid, em 2002, os governos estabelecem um Plano de Ação baseado no compromisso de que os velhos podem contribuir para o desenvolvimento da sociedade, o que implica que os governos coloquem em suas politicas de desenvolvimento econômico e social o tema do envelhecimento.

Essa chamada propositiva, que começa no século $\mathrm{XX}$ e tem continuidade no século XXI, além de alertar o mundo sobre a situação dos velhos, ajuda a pensar o envelhecimento para o século XXI. Essa iniciativa, que tem início nas Assembleias Mundiais do Envelhecimento, se fortalece com o documento editado pela Organização Mundial da Saúde, denominado "Envelhecimento Ativo". Sob o comando de um 
grupo de especialistas, liderado por Alexandre Kalache, o documento evidencia que é possivel envelhecer ativamente, desde que haja uma atenção para os fatores que o determinam. Esse documento modifica a visão e a imagem do velho do passado, associadas à doença, e propõe uma velhice saudável, integrada e ativa.

Nesse sentido, a representação da velhice por períodos históricos mostra que a sociedade, à medida que evolui, trata do processo de envelhecimento de forma distinta e que pelas características que a sociedade moderna trouxe ao velho o desejo de ter um lugar que lhe pertence na sociedade e não fora dela.

Segundo os resultados da pesquisa, das narrativas dos jovens emergiram três categorias que evidenciam as percepções que eles têm dos velhos e de como gostariam de ser quando velhos: velhos autônomos e independentes, velhos em família e velhos acompanhando a força da cultura do momento. Nos depoimentos, fica visivel o despreparo para o enfrentamento dessa etapa de vida, a partir da própria juventude.

\section{Velhos autônomos e independentes}

A imagem de velhos autônomos e independentes preponderou nas entrevistas. A maioria dos jovens se vê como velhos integrados, ativos, participando da vida familiar e social. No conjunto das narrativas, evidenciam que seguem realizando as mesmas atividades que desenvolveram ao longo da vida, sem problemas, como se o tempo não tivesse trazido marcas de sua presença.

- Praticando exercícios fisicos regularmente, com autonomia para realizar minhas AVD's, respeitando as diminuições de funcionalidade da idade, mas me mantendo completamente independente. (Aluno 3, sexo feminino, 36 anos). 
- Ter condições financeiras de me manter independente, ter um ciclo de amizades, frequentar atividades que me deem prazer, como shows, restaurantes, cinemas, praia, teatros... Eu vou à praia caminhar e tomar sol de manhã, pratico atividades físicas, leio, converso, convivo com pessoas que me querem bem e me respeitam. Me sinto útil e amada, porque as pessoas que me conhecem gostam de ouvir minhas histórias de vida, meus conselhos, apreciam minha companhia e me tratarem com respeito. (Aluno 3, sexo feminino, 36 anos)

- Eu me vejo autônoma e independente, buscando nas atividades sociais o fortalecimento de vínculos comunitários. (Aluno 11, sexo feminino, 26 anos)

- Espero que quando eu tenha 92 anos esteja lúcida. E com capacidades fisicas boas para que consiga me locomover com autonomia. (Aluno 41, sexo feminino, 22 anos)

Essa forma de encarar o envelhecimento mostra que mesmos as diferenças que possam existir entre aqueles que têm 20 a 30 anos para os que têm 90 anos não podem ser entendidas como uma mera prorrogação de tempos, sem consequências e evidências do processo. Sessenta, setenta anos de diferença entre um ser e outro reflete que alguns estão começando a caminhada no mundo produtivo e outros já a trilharam e, consequentemente, a representação não pode ser a mesma. O tempo da diferença é o mesmo tempo que a sociedade atribui a um indivíduo para ser idoso. Então, o que essa representação significa? Uma negação ou um despreparo para projetar e visualizar o futuro, contando que as ações presentes influenciarão ou não o "vir a ser".

A condição de autonomia e independência se apresenta como uma forte característica que os jovens aspiram na sua velhice. Os conceitos de autonomia e independência são predicados do envelhecimento ativo, juntamente com a qualidade e a expectativa de vida saudável (OMS, 2005). A proposta de envelhecimento ativo postula que 
essas condições, necessárias para um "envelhecimento ativo", pressupõem uma história de vida com autonomia, independência, vida saudável e com qualidade.

Bobbio, em sua autobiografia Tempo da memória, diz que quando pensava em velho, lembrava apenas de uma bisavó paterna e que não recordava ter conhecido pessoas com mais de oitenta anos. Entretanto, tece um comentário sobre o pai, que morreu aos 65 anos de idade, e que para ele essa imagem teve um significado especial.

Nunca imaginei viver tanto. Não me lembro de pessoas que morreram com mais de oitenta anos em minha família paterna, nem na materna. A única que ficou presente na minha memória é uma bisavó paterna. Meu pai, com quem me pareço, cuja idade nunca acreditei ultrapassar, morreu aos 65 anos. Entrei na casa dos sessenta, quando começaram, também na Itália, os anos da "contestação", quando os filhos se rebelaram contra os pais. Senti-me de súbito enve1hecido. Escrevi: "Seria insensato, além de inútil, maquiar-se para fazer desaparecer as rugas e fingir uma juventude que já ficou para trás" (BOBBIO, 1997, p. 33).

Nessa mesma obra, Bobbio cita um trecho de Achille Campanille, um humorista de sua geração que dizia:

Esses velhos sempre me espantaram... Como é que conseguiram superar sãos e salvos tantos perigos e chegar à vida avançada? Como fizeram para não morrer atropelados, como lograram superar as doenças mortais, como conseguiram evitar uma telha, uma agressão, um acidente de trem, um naufrágio, um raio, um tombo, um tiro? Realmente esses velhos devem ter parte com o demônio! E alguns deles ainda ousam atravessar a rua lentamente... estarão loucos? (BOBBIO, 1997, p. 35). 
As ponderações feitas por esse grande humanista italiano mostram que para cada época vemos a velhice de forma própria, mas ela chega sempre para aqueles que duram mais. $\mathrm{Na}$ experiência narrada por Bobbio, para cada época há uma referência de velho associada às vivências que cada indivíduo teve nas suas relações.

\section{Velhos em familia}

Nas entrevistas ficou evidente que o modelo de velho no imaginário dos entrevistados está associado ao que viveram em família, com seus pais, avós, tios ou bisavós. A falta de um modelo que dê conta do seu futuro reflete a perspectiva de que muitos jovens ainda não pensaram sobre como querem envelhecer. Estão ainda presos às experiências que tiveram com seus familiares e projetam para o futuro essa experiência.

O modelo de família, no qual os jovens estão inseridos, influi na percepção que têm sobre a velhice, e os cuidados ou não dos seus membros afetam essa representação. O modelo de família atual, que ainda está baseado na família nuclear, mesmo com a presença de muitos arranjos familiares surgidos nas últimas décadas, destaca no grupo familiar características como individualismo, instabilidade, mobilidade, ausência de algumas regras básicas de convivência no mesmo teto, excesso de liberdade e muitos conflitos nas relações interpessoais. Esse modelo, em transição, aparece nas falas dos jovens, ainda como centro de união dos membros da família, como o lugar da proteção e dos cuidados, da reprodução e do aprendizado dos valores e da inserção social.

- Acredito que quando tiver 92 anos, serei uma velhinha com cabelos bem brancos e grisalhos, com o rosto bastante enrugado, porém acho que serei ainda vaidosa, portanto serei uma velha cuidada. Penso que conseguirei 
me movimentar, caminhar em parques com meus netos e filhos, quem sabe até bisnetos. Provavelmente usarei óculos e não ouvirei tão bem quanto hoje. Acredito que serei um pouco chata, reclamona, e dificilmente aceitarei opiniões de outras pessoas, mas acredito que serei uma velha divertida, brincalhona. (Aluno 21, sexo feminino, 20 anos).

- Com 92 anos, se ainda estiver viva, estarei um pouco acima do peso, esquecendo-me de tomar remédios e de quem são as pessoas, mas adorando assistir à novela. Convivo com minha família, porque eles me dizem quem são e eu já não lembro. Com a vida que passou me sinto realizada, por isso vivo feliz mesmo, sem lembrar de tudo, pois marcas ficaram para sempre... hoje caminho apenas dentro de casa, às vezes saio na rua para pegar um sol. (Aluno 23, sexo feminino, 19 anos).

- Ao chegar aos 92 anos pretendo estar com meu marido, meus filhos, netos e bisnetos. Quero poder ter condições ótimas fisicamente e mentalmente, para ainda poder auxiliar minha família no que for preciso. Quero continuar com a vontade de passear, viajar, assistir séries e filmes, ler e principalmente quero cozinhar muito ainda e ter o principal: amor, amor para passar para meus familiares e falar a eles o quão bom é viver. (Aluno 42, sexo feminino, 20 anos).

Em muitos relatos, a família da qual esses jovens se remetem cumpre ainda as funções tradicionais que marcaram as relações familiares, de um modelo tradicional de família, em que há a presença de vários papéis definidos, sendo que os jovens relatam que esperam chegar a exercer esses papéis. Parece contraditório que o modelo de referência tenha como suporte as vivências baseadas no modelo de família nuclear, mesmo que nelas esteja presente uma série de ambiguidades, que a instituiçãofamília carrega consigo. O casamento romântico ainda aparece como destaque, e as relações afetivas são expressões frequentes. 
- Quero estar financeiramente estável, aproveitar para viajar, curtir os netos, os filhos. Ser uma pessoa velha de idade, mas nova de espírito. (Aluno 27, sexo feminino, 22 anos).

- Me vejo com núcleo familiar afetuoso, com filhos, netos e bisnetos. Espero ter meu companheiro ao meu lado tão saudável quanto eu. Buscando sempre poder aprender com as transformações, conhecendo o novo e poder compartilhar meus conhecimentos com os outros. (Aluno 11, sexo feminino, 26 anos).

- Ter filhos e que esses filhos me deem netos para que, nos fins de semana, eu me sente em frente à lareira para contar histórias, rodeada pela minha paixão maior "meus gatos". (Aluno 12, sexo feminino, 25 anos).

- Sou um avô brincalhão, e muito próximo de meus filhos e netos. Penso em ser um exemplo para meus parentes mais jovens, na questão de estar sempre disposto e demonstrando alegria, apesar de problemas de saúde e/ou de qualquer outra origem. (Aluno 45, sexo masculino, 23 anos).

Os jovens falam de como querem ser quando tiverem 92 anos, como se estivessem no mesmo tempo e no mesmo espaço do qual falam no presente. Tomam para si as experiências que tiveram e o projeto de futuro está como se não tivessem envelhecido.

- Frequentar atividades que me deem prazer, como shows, restaurantes, cinemas, praia, teatros... (Aluno 4, sexo feminino, 30 anos).

- Gostaria e me imagino em ser uma idosa com vaidade, fazendo atividades fisicas, leituras, saindo com amigas(os) para jantar, dançar. (Aluno 12, sexo feminino, 24 anos).

- Sou uma pessoa alegre e extrovertida, penso sempre em inovar, mudar e crescer na vida. Acredito que, ao me imaginar com 92 anos de idade, serei uma idosa alegre, de bem com a vida. (Aluna 16, sexo feminino, 22 anos). 


\section{Influência da cultura}

Nas narrativas dos jovens, fica evidente a importância que os mesmos atribuem ao velho ativo, integrado, participativo da vida social. Detalhes postulados pela sociedade contemporânea, que valoriza os beneficios de uma vida saudável, em que os cuidados com o corpo e a mente são evidentes, e as marcas da velhice são escondidas pelos exageros que o avanço da tecnologia ofereceu ao velho de hoje. Como dito anteriormente, o próprio documento do "Envelhecimento Ativo", proposto pela Organização Mundial da Saúde, mostra que é possivel envelhecer com saúde, integrado, seguro e com dignidade, quando a preparação para o envelhecimento ocorre ao longo da vida.

Entretanto, estudos ${ }^{1}$ têm demonstrado que muitos indivíduos se prepararam para envelhecer e que muitos são surpreendidos quando eventos lhes trouxeram à consciência que tinham envelhecido. É importante lembrar que os velhos de hoje tiveram um ganho de tempo de vida, diferente daquele dos seus pais e avós, que, com muita frequência, morriam cedo ou chegavam aos sessenta anos com muitas dificuldades. Esse ganho, em termos de mais anos de vida, fez com que muitos acreditassem que teriam todo o tempo disponivel para envelhecer e, nesse sentido, parece um sentimento comum, que vimos em outras pesquisas, que é a negação do envelhecimento. "Todos envelhecem menos eu." "O outro é velho, mas eu não." "Quem é velho?" Essas afirmações representam que a negação da velhice só é superada se ocorrer uma preparação e um reconhecimento dessa condição. Ser velho não é uma ilusão,

1 DEBERT, Guita Grin. A reinvenção da velhice. São Paulo: Edusp, 1999. PY, Ligia. Velhice nos arredores da morte: a interdependência na relação entre idosos e seus familiares. Porto Alegre: Edipucrs, 2004. MORAGAS, Ricardo Moragas. Gerontologia social: envelhecimento e qualidade de vida. São Paulo: Paulinas, 1997. 
representa ter realizado a caminhada pela vida, que para cada ser é própria, peculiar e suigeneris; não pode ser feita pelo outro. Nesse sentido, os jovens expressam que quando forem velhos querem poder realizar atividades como se fossem jovens, como se não existisse nenhuma diferença entre as faixas etárias. Os relatos abaixo foram extraídos para apontar essa situação de imaginar a sua velhice.

- Durante a semana estudo e trabalho, não tenho horário disponivel para praticar algum esporte. No final de semana, procuro sair para caminhar e conhecer novos lugares, me desligando de outros assuntos. Meu modo de pensar é sempre analisando o que é correto, sendo sempre sincera com as pessoas. Me considero uma pessoa sonhadora e com objetivos a serem alcançados. Gosto de conviver com pessoas que me fazem bem. Amo estar perto da minha familia. (Aluno 33, sexo feminino, 21 anos).

- Aos 92 anos espero ainda manter uma vida ativa, com autonomia para realizar o que desejo e o que necessito. Também com as funções mentais preservadas, com a cognição preservada, com os aspectos comportamentais ativos. Nesta idade costumo ler bastante, aprender coisas novas, ter um bom relacionamento com a família. Me sinto feliz e agradecida por todos esses anos que vivi, e como os vivi para chegar até aqui. (Aluno 31, sexo feminino, 21 anos).

A negação da velhice não é feita só por velhos. Também ocorre com os jovens, quando não aceitam as condições de envelhecimento de seus pais, de seus avós ou mesmo de bisavós e exigem que os mesmos continuem realizando atividades como se o tempo não tivesse passado. Muitos indivíduos apagam esse tempo que transformou seus familiares e lhes tirou o vigor que os identificava, marcado pela presteza, agilidade, disponibilidade e atenção contínua. A falta de compreensão dessas alterações, provocadas pelo processo de envelhecimento, gera muitos conflitos, quando as exigências continuam a ser postas na mesa, como se os velhos não tivessem sofrido a ação 
do tempo, corroborada pelas ações dos próprios velhos, que negam que envelheceram. Entretanto, a negação não acontece apenas com aqueles que amamos, acontece com todos, porque a própria sociedade reconhece o envelhecimento apenas quando lhe interessa.

\section{Algumas considerações}

Para entender o processo de envelhecimento, é necessário aprender mais sobre as mudanças normais associadas à idade, que aumentam a vulnerabilidade a essas e outras questões relacionadas à velhice. Essa afirmação implica que para entender os aspectos sociais do envelhecimento, torna-se imprescindivel nos estudos científicos identificar quais são os desafios para poder enfrentá-los.

É comum ficarmos surpresos com os dados da população idosa, mas sem eles não temos como identificar e comparar as semelhanças e as diferenças que ocorrem nos grupos etários, principalmente os mais longevos, dos quais não tínhamos anteriormente referência, bem como saber quem são os jovens de hoje, como pensam e como estão sendo preparados para os desafios postos pela sociedade.

Debert (1999, p. 43) comenta que "o fato universal de que as diferenças entre idades estão presentes em todas as sociedades tem sido explicado como fruto de uma necessidade da vida social, expressa em termos do processo de socialização". Mas o que realmente quer destacar é que, para desenvolver algumas atividades, é necessária uma certa capacidade física e essa tem a ver com os diferentes estágios de desenvolvimento biológico. Nesse sentido, Debert (1999, p. 43) complementa que as atividades relacionadas a diferentes estágios de desenvolvimento biológico "pressupõe-se o aspecto cumulativo dos vários conhecimentos necessários ao preenchimento dos papéis sociais, cuja aquisição consome tempo e implica uma progressão etária". 
Essa colocação mostra que não é simples para os jovens ter um entendimento de todo o processo pelo qual os indivíduos passam para chegar à velhice e que essas etapas não são comuns e semelhantes aos que envelhecem, levando em consideração que o processo de envelhecimento é heterogêneo.

As representações da velhice, por parte dos jovens, mostram que os mesmos imaginam os velhos como se fossem sempre jovens e, na maioria, sem problemas, sem fragilidades, encarando a vida como se a mesma não lhes apresentasse os desafios do próprio envelhecimento. As categorias analiticas que nasceram das narrativas dos jovens ilustram essas representações de velhos saudáveis, presentes, integrados na estrutura familiar, fazendo o que sempre fizeram, acompanhados pelos seus afetos e com poucas dificuldades que a idade traz. Das três categorias criadas, todas se relacionam. Autonomia e independência são atributos importantes na velhice e precisam ser cultivadas desde cedo. Vida em família também aparece como uma constante, sendo que os jovens não se veem sozinhos e sim acompanhados pelos familiares, o que implica aceitação dos papéis que a família ainda carrega consigo. A influência da cultura indica e reflete atividades que são comuns na vida de jovens, como ir a restaurantes, ao cinema, ao teatro; fazer leituras; ir à praia, a diversões, estudos. O que chama a atenção é que não aparece nem a religião nem o trabalho como atividade comum, necessária e valorativa para enfrentar a velhice.

As narrativas dos jovens corroboram com o que Debert (1999, p.14) postula ao tratar da reinvenção da velhice, quando afirma que, contemporaneamente, tende-se a rever os estereótipos associados ao envelhecimento. Essa afirmação está sustentada na ideia de que a representação negativa foi substituída "pela consideração de que os estágios mais avançados da vida são momentos propícios para novas conquistas, guiados pela busca do prazer e da 
satisfação pessoal". O estudo aponta para esse caminho sem incluir na discussão crítica a visão classista, associada à posição que os velhos ocuparam ao longo da vida e das condições sociais e econômicas que enfrentam no presente enquanto velhos.

O estudo não tem pretensões de estabelecer generalizações, mas de promover uma reflexão com jovens sobre o preparo para o envelhecimento ao longo da vida. Talvez a experiência pudesse ser repetida com crianças, cujos resultados certamente seriam distintos, mesmo que a intenção tenha sido apenas de desencadear uma discussão critica sobre os referenciais que são utilizados para categorizar os velhos. 


\section{Referências}

BEAUVOIR, Simone. A Velhice. Trad. de Maria Helena Franco Monteiro. Rio de Janeiro: Nova Fronteira, 1990.

BOBBIO, Norberto. Tempo da Memória de Senectude e outros escritos autobiográficos. Rio de Janeiro: Campus, 1997.

CALDAS, Célia Pereira. Introdução à gerontologia. In: VERAS, Renato; LOURENÇO, Roberto. Formação humana em geriatria e gerontologia: uma perspectiva interdisciplinar. Rio de Janeiro: UFRJ, 2010.

CÍCERO, Marco Túlio. Saber envelhecer. Trad. de Paulo Neves. Porto Alegre: L\&PM, 2001.

DEBERT, Guita Grin. A reinvenção da velhice: socialização e processos de reprivatização do envelhecimento. São Paulo: Edusp/Fapesp, 1999.

ENVELHECIMENTO ATIVO: uma politica de saúde. Trad. Suzana Gontijo. Brasília: Organização Pan-Americana da Saúde, 2005.

ENVELHECIMENTO ATIVO: um marco politico em resposta à revolução da longevidade. Centro Internacional de Longevidade Brasil. Rio de Janeiro, RJ, Brasil, 2015.

GOFFMAN, Erving. A representação do Eu na vida cotidiana. Petrópolis; Vozes, 2011.

HORIZONTES / Aspectos prácticos del envejecimiento y el desarrollo. HelpAge Internacional, n. 64, abril 2004.

MORAES, Roque. Análise de conteúdo: limites e possibilidades. In: ENGERS, M.E.A. (Org.) Paradigmas e metodologias de pesquisa em educação. Porto Alegre: Ed. UFRGS, 1994. 
NERI, Anita Liberalesso. O fruto dá sementes: processos de amadurecimento e desenvolvimento. In: NERI, Anita Liberalesso (Org.). Maturidade e velhice: trajetórias individuais e socioculturais. Campinas: Papirus, 2001.

ORGANIZAÇÃO MUNDIAL DA SAUDE. Envelhecimento ativo: uma política de saúde / World Health Organization. Tradução Suzana Gontijo. Brasília: Organização Pan-Americana da Saúde, 2005. 60p. 